\title{
Comunicaciones entre el Alto Guadalquivir y el Mediterráneo en la época romana
}

\author{
Martín JimÉnez CoBo
}

\section{VÍA CÁSTULO-CARTHAGO NOVA}

El Alto Guadalquivir tuvo un papel muy importante tanto en las luchas de conquista de romanos y cartagineses, como en la economía de unos y otros.

Cástulo, ciudad ibérica y romana situada a unos $5 \mathrm{~km}$ al Sur de la actual Linares, fue famosa en la antigüedad principalmente por sus minas de plata y plomo. Es además un territorio fértil para la agricultura y para la ganadería, y de gran valor estratégico para el control de los pasos al valle del Guadalquivir.

Roma y Cartago tuvieron que utilizar mucho las rutas que ponian en contacto las regiones giennenses con los puertos y vías costeromediterráneas.

Los autores antiguos nos han transmitido poca información sobre estas rutas. Estrabón, al describir la vía levantina que desde Roma llegaba a Bética, sólo dice que después de pasar por el Campo Espartario pasaba por Cástulo y Obulco ${ }^{1}$.

$\mathrm{Y}$ otros autores más modernos, en el trayecto, por ejemplo, entre Acci y Mentesa, sólo dicen que pasaba por el término de Cambil, sin precisar la localización de Viniolis y Agatucci, y mucho menos los trazados entre cada una de estas mansiones.

Strabon, Geographiká, II, 4, 9. Traducción por Garcia Bellido, A., España y los españoles hace dos mil años. Madrid, Austral, 1968, pág. 140. 
A. Blázquez, al hablar del tramo entre Acci y Mentesa, dice que está muy borrado, pues el ímpetu de las aguas de lluvia hace poco duraderas las obras de fábrica ${ }^{2}$. Esto se puede aplicar no sólo a este tramo, sino a todo el comprendido entre Cástulo y Carthago Nova. Y no solamente no se encuentran obras de fábrica de la vía propiamente dicha, sino que los restos de ciudades también están borrados. Y lugares donde se ha oído decir con frecuencia que había grandes restos de población romana, cuando va uno con la esperanza de contemplarlos, se encuentra con que no se puede ver nada y nadie sabe que existiese ningún resto romano. Tal es el caso de Arbuniel, del que había leído en Góngora, Ceán y Fita que había numerosas muestras de población romana, y al llegar allí casi nadie tenía la menor idea de que había allí algo interesante.

El presente trabajo tiene por objeto contribuir al conocimiento de las vías romanas de la zona del Alto Guadalquivir, principalmente las que la comunicaban con el Mediterráneo.

Las principales eran cuatro:

1. La que atravesaba el Saltus Castulonensis (parte oriental de Sierra Morena) y por Albacete y Alicante se dirigía a Saetabis, descrita en los Vasos de Vicarello y en parte en el Itinerario de Antonino y en el Anónimo de Rávena.

2. La que enlazaba a Cástulo con Carthago Nova siguiendo la cuenca del Guadalbullón y después el Surco Intrabético.

3. La que el Itinerario de Antonino llama A Castulone Malacam, por la depresión del Guadiana Menor, pasaba por Acci, por la región de Almeria, y por las costas de Almeria y Granada se dirigia a Malaca.

4. La que desde la campiña de Jaén iba por Martos y Alcaudete al Sur de la provincia de Córdoba donde se unía a la que desde Córduba se dirigía a Malaca por Anticaria.

De ellas estudiamos en este trabajo la segunda: la que desde Jaén entraba en la provincia de Granada por la cuenca del río Guadalbullón y giraba a Guadix por Iznalloz, Bogarre y Huélago, para seguir después a lo largo del Surco Intrabético.

Esta vía fue estudiada y descrita parcialmente (trayecto Baza-Lorca) en el siglo XVIII por A. J. Navarro, Abad de Baza, en una Memoria enviada a

B Blázouez y Delgado Aguilera, A. y Blázouez Jiménez, A., Via romana de Cartagena a Castulo, Memoria de la JSEA, n. ${ }^{\circ} 59$. Madrid 1923, pág. 17. 





la Real Academia de la Historia en 1798, cuyo manuscrito se conserva en la Biblioteca de dicha Corporación ${ }^{3}$ y fue publicada en $1916^{4}$.

En el siglo xix hablaron algo de ella $M$. Góngora ${ }^{5}$ y Ceán Bermúdez ${ }^{6}$. En el siglo xx fue estudiada por A. Blázquez Delgado Aguilera y A. Blázquez Jiménez ${ }^{7}$.

Recientemente $P$. Sillières ha publicado un extenso trabajo sobre las vías de comunicación de Hispania Meridional y dedica a esta vía parte del Capítulo I (Libro II) y hace un estudio más amplio y completo que los anteriores ${ }^{8}$.

En la revista El Miliario Extravagante publiqué yo en julio y septiembre de 1989 sendos artículos sobre los trayectos Mentesa-Acci y CástuloMentesa. El Director G. Arias además de sus acostumbradas apostillas a cada artículo, siguió tratando de la misma materia en los dos números siguientes ${ }^{9}$.

\section{FUENTES}

Entre los geógrafos antiguos nos habla de esta vía Estrabón en un texto bastante controvertido, porque se presta a la confusión:

«Por este lugar (Los exvotos de Pompeyo en los Pirineos Orientales) pasa la vía que llaman exterior y que va desde Italia a Iberia, concretamente a Bética. Esta vía se acerca a veces al mar: otras se aleja de él, sobre todo en los tramos occidentales. Tras los trofeos de Pompeyo va a Tarraco, pasando por luncarion Pedion, por los Beteres y por Marathonion Pedion, así llamado por la abundancia de marathon (hinojo) que alii crece. De Tarraco va al paso del lber en la ciudad de Dertosa; de aquí, por la ciudad de Saguntum y la de Saitabis, apártase paulatinamente

3 Biblioteca Nacional, Est. 27, gr. 6., E. n. ${ }^{\circ} 165$.

4 FITA, F., "Inscripciones romanas de Chirivel y Galera", Boletin de la Real Academia de la Historia, n. ${ }^{\circ}$ LXIX, 1916, págs. 486-489.

5 Góngora Martinez, M., Viaje literario por las provincias de Jaén y Granada. Ms. de la Real Academia de la Historia, leg. 9-5359, fols. 23-24.

- Cean Bermúdez, A., Sumario de las Antigüedades romanas que hay en España. Madrid 1832. Publicado en la revista $D$. Lope de Sosa, Jaén (1917, 1918 y 1919).

7 Blázquez y Delgado Aguilera, A. y BlázQuez Jiménez, A., Op. cit., págs. 14-17.

- Sillieres, P., Les voies de communication de l'Hispanie meridionale, Centre Pierre Paris. Paris 1990, págs. 275-288.

${ }^{9}$ JimÉnez COBO, M., "Vías romanas de la provincia de Jaén", Miliario Extravagante, n. ${ }^{\circ} 23$, 1989, págs. 2-6. "Más sobre Mentesa Bastia y sus vias», Miliario Extravagante, n. ${ }^{\circ} 24,1989$, págs. 9-12. "Ecos del enredo bastetano", Miliario Extravagante, n. ${ }^{\circ} 26,1990$, págs. 4-6. ARIAS BONET, G., «El enredo bastetano», Miliario Extravagante, n. ${ }^{\circ} 25,1990$, págs. 10-18. 
de la costa, llegando luego al llamado Spartarion Pedion, un gran campo sin agua, donde crece abundantemente la especie de esparto que sirve para tejer cuerdas y se exporta a todos los países, principalmente a Italia. Antes la vía cruzaba por medio del Campo (del esparto) y por Egelastai; mas era difícil y larga. Ahora, por ello, transcurre junto a la marina y no cruza mas que una pequeña parte del espartizal. Luego pasa, como la antigua vía, por Cástulo y Obulco para seguir de allá rumbo a Córduba y Gades" ${ }^{10}$.

El texto de Estrabón se presta a confusión ya que, a partir de Saetabis, la vía de Cástulo por Carthago Nova y Acci pasa más próxima a la costa, «la marina» en frase de Estrabón, pero no es más corta. En cambio la vía por Albacete y Ciudad Real es más corta, pero alejada de la "marina».

Tanto si se considera el "Campo Espartario" el próximo a Carthago Nova, como si se sostiene que estaba por Albacete, Estrabón sólo dice que pasaba por Cástulo y Obulco para seguir rumbo a Córduba y Gades.

La principal fuente literaria para el conocimiento de la vía es el Itinerario de Antonino, que en 401,5-402,5 (numeración de Wesseling) la describe del modo siguiente:

\section{1,5. Karthagine Spartaria}

6. Eliocroca m.pág. XLIV

7. Ad Morum m.pág. XXIV

8. Basti m.pág. XVI

402,1. Acci m.pág. XXV

2. Agatucci m.pág. XXVill

3. Viniolis m.pág. XXIV

4. Mentesa Bastiam m.pág. XX

5. Castulone m.pág. XXII

Las otras fuentes itinerarias, Vasos de Vicarello, Anónimo de Rávena, Tabla Peutingeriana, etc., no mencionan esta vía. Las geográficas, Plinio el Viejo, Mela, C. Ptolomeo y Marciano de Hereaclea nos proporcionan valiosos datos para el conocimiento de la región, pero tampoco hablan de la vía.

Quedan las fuentes epigráficas, sobre todo los miliarios, de los que se conoce un número considerable: conocemos 16 , de los que se conservan

10 Strabon, Op. cit., III, 4, 9. 
nueve; de los demás tenemos noticias por diversos autores de siglos pasados.

Se localizan así: uno en La Guardia (Jaén), cuatro en La Cerradura, también en el término de La Guardia, dos en Cúllar de Baza (Granada), tres en Chirivel y su término (Almería), tres en el término de Vélez Rubio (Almeria), uno en Lorca, Valdearazos y Totana (Murcia).

Se podrian añadir otro en Albanchez (Jaén), probablemente procedente de Cerro Alcalá, posible paso de la vía en el trayecto Cástulo-Mentesa, uno de Guadix, donde esta vía se cruzaba con la de Cástulo-Malaca, y otro en Cúllar, del que habla el Abad Navarro, pero sin ofrecernos la transcripción. En Mengíbar, otro posible paso del trayecto Cástulo-Mentesa, se conservan otros dos, que también pueden pertenecer a otras vías.

Seis de los miliarios son del tiempo de Augusto y está dedicado uno a cada uno de los emperadores siguientes: Adriano, Maximino, Constantino, Crispo, Numeriano, Caracalla y Constancio Cloro. El de Albanchez a Maximiano, el de Guadix a Póstumo y los de Mengíbar a Claudio. Los restantes son ilegibles.

Aunque algunos autores de los siglos pasados hablan de abundantes vestigios de la vía romana, actualmente son muy pocos los que se conservan. Hay un puente atribuido a los romanos en Iznalloz (Granada) y restos de calzada en las proximidades de Gor (Granada) en el trayecto Guadix-Baza. Han aparecido restos de época romana en muchos lugares a lo largo del trayecto, pero de la vía propiamente dicha apenas queda nada.

\section{LA VÍA CASTVLO-CARTHAGO NOVA}

Es el último tramo de la que el Itinerario de Antonino denomina $A b$ Arelato Narbone, inde Tarracone, Karthagine Spartaria, Castulone. (396,1 ss.) Aunque aqui la estudiamos en sentido inverso al que pone el Itinerario, por haber centrado el trabajo principalmente en las comunicaciones del Alto Guadalquivir.

Las distancias del Itinerario plantean diversos problemas:

En unos códigos se ponen CClII millas $(300,743 \mathrm{~km})$.

En otro CCCII y CCCIII $(447,262$ y $448,743 \mathrm{~km}$ ) (Itin. 396,4$)$.

La segunda cifra (302 millas) no coincide con la suma de las distancias ni con la realidad, que es algo más de 260 millas (unos $390 \mathrm{~km}$ ). 
La primera cifra (203 millas) coincide con la suma de las parciales, pero no con la realidad. En las carreteras actuales, que siguen en general igual o parecido trazado, la distancia entre Cástulo y Carthago Nova es de unos $390 \mathrm{~km}$, unas 263 millas, cifra muy alejada de las 203 de la suma de las parciales.

A. Blázquez ${ }^{11}$ cree que hay algún error en los copistas y propone que se modifique alguna de las cifras. Por esto, si la tercera cifra que es una $C$ en unos códices $y$ una $I$ en otros la sustituimos por una $X$ o una $V$ tendremos CCXII o CCVII.

La verdad es que esta modificación resuelve poco. La cifra de 212 o la de 207 millas también están muy alejadas de la distancia real.

Mucho más fácil que confundir una $X \circ$ una $V$ con la $C$ es que los copistas confundieran la $\mathrm{L}$ con la $\mathrm{C}$ y pusieran CCCII en lugar de CCLII. Las 252 millas (o 253 según otros códices) que resultarían de esta sustitución sí se aproximan a la distancia real.

$Y$ aunque la suma de las distancias parciales da 203, si tenemos en cuenta que entre Basti y Morum hay una laguna evidente de unas 31 millas, como después veremos, y entre Cástulo y Mentesa parece haber también un error de unas 10 millas, y entre Acci y Basti parece que debe poner XXX en lugar de XXV, la suma total daría 249 millas, más 4 entre Eliocroca y Carthago Nova (algunos códices ponen 48 en lugar de 44), las 253 resultantes podrían ser las que realmente figuraban en el original del Itinerario.

En el tramo Cástulo-Mentesa las 22 millas son insuficientes, por lo que, según Roldán Hervás, habría que corregirlas en XXXI1 ${ }^{12}$. Entre Acci y Carthago Nova también son insuficientes las 109 del Itinerario. A. Blázquez supone que aquí se ha omitido alguna mansión, que él supone ser Agatucci, que según él, estaba mal colocada en el trayecto Cástulo-Acci. Nosotros pensamos que Agatucci no estaba demás en el trayecto anterior, pero que efectivamente entre Basti y Morum falta una mansión y unas 31 millas ${ }^{13}$.

\section{MANSIONES Y TRAYECTOS}

CASTVLO. Fue la ciudad más importante del Alto Guadalquivir en la época romana. En el Itinerario Antonino figura como punto de partida o de llegada de las vías más notables del Sur de la Península.

Blazouez y Delgado Aguilera, A. y Blázquez Jiménez, A., Op. cit., pág. 15.

12 Roldán Hervas, J. M., Itineraria Hispana, Universidad de Valladolid, Departamento de Historia Antigua. Valladolid 1975, pág. 52.

13 Blázquez y Delgado Aguilera, A. y Blázouez Jiménez, A., Op. cit., pág. 15. 
En los Vasos de Vicarello I y III figura en la ruta de Gades a Roma (en el II y IV figura la mansión Ad Aras, probablemente la actual Linares). En el Anónimo de Rávena, aunque ordenado de forma diferente, figuran varios trayectos de esa misma ruta entre Cástulo y Saetabis.

Estrabón cita en diversas ocasiones a la ciudad de Cástulo: "Las ciudades principales de Oretania son Cástulo y Oria" ${ }^{14}$.

Es citada también por otros autores de la Antigüedad: Plinio, Ptolomeo, Polibio, Plutarco, Tito Livio, Silio Itálico, etc.

La ciudad estuvo situada a unos $5 \mathrm{~km}$ al Sur de la actual Linares, junto a la orilla derecha del Guadalimar. Desde el antiguo camino de Linares a Torreblascopedro todavía se pueden ver restos de muralla, y el terreno, incluso el que aún está sin excavar, que es la mayor parte, está lleno de piedras y cascotes, restos de los edificios demolidos de la ciudad.

La localización no ha sido difícil porque está atestiguada ya desde el Renacimiento, en que se podía aún observar a simple vista restos de edificios y hasta la distribución de calles. Aunque la mayor parte de los restos encontrados son de época romana, se han encontrado también vestigios de la época argárica y de las colonizaciones de fenicios, griegos y cartagineses. La explotación de las minas de Sierra Morena le dieron importancia y desde épocas remotas Cástulo fue el centro comercial del mineral y la residencia tanto de trabajadores como de empleados y comerciantes. Abandonada al final de la dominación árabe y conquistada en el siglo XIII por Fernando III (en realidad un despoblado) fue cedida a Baeza y después a la aldea de Linares. En el siglo $x v$ era refugio de bandidos y salteadores, por lo que las autoridades de Baeza y Linares ordenaron la destrucción de los edificios que aún quedaban.

CASTVLO-AD ARAS. Los Vasos de Vicarello II y IV no citan a Cástulo en el camino entre Ad Noulas (Villanueva de la Reina) y Ad Morum (Navas de S. Juan), sino la mansión Ad Aras. Probablemente habría una desviación del camino para evitar el paso por Cástulo y una mansión a unos 4 ó $5 \mathrm{~km}$ al Norte que en su origen fue tal vez un conjunto de barracones para los obreros de las minas y establecimientos para la elaboración del mineral y después sirvió de mansión para los viajeros que no querían detenerse en Cástulo.

El lugar más probable es el mismo casco de la actual ciudad de Linares, en las proximidades de la Fuente del Pisar; o en Magdalena de

14 Strabon, Op. cit., III, 3, 2. 
Castro, cortijada y cruce de caminos en la carretera de Linares a Vadollano, que está sobre la misma vía.

TRAYECTO CASTVLO-MENTESA. Borrados por el tiempo los vestigios de la vía, tenemos que guiarnos por el trazado de caminos antiguos y por la localización de lugares en que han aparecido restos de ciudades o de poblamiento romano.

Sobre el trayecto Cástulo-Mentesa son varias las hipótesis.

A. Blázquez, siguiendo a M. Góngora, lo sitúa pasando desde Cástulo a Torreblascopedro y a la Cortijada de Posadas Ricas, junto al Guadalquivir. Pasaba el río por vado y seguía hacia el Sur dejando a la derecha el cortijo de Recena hasta la ciudad de Cerro Alcalá, entre Jimena y Mancha Real, y desde aquí a Mentesa ${ }^{15}$.

A este lugar lo llama Hübner Oppidum ignotum prope Mancha Real et Jimena situm, y dice de él: "En el camino de Jaén a Jódar, a la orilla izquierda del riachuelo de Torres, casi a una legua de Torres, otro tanto de Jimena y a dos de Mancha Real, Góngora descubrió restos de un pueblo antiguo de época romana que el vulgo llama ciudad de Alcalá, indicando con este nombre algún tipo de castillo del tiempo de moros» ${ }^{16}$.

Todavía quedan algunos restos de muro y han aparecido muchas piezas arqueológicas, entre ellas numerosas inscripciones, una de las cuales dedicada a una Cornelia Sillibori por el Pueblo Latoniense, por lo que podría localizarse aquí el Ossigi Latonium de que habla Plinio ${ }^{17}$.

Desde Cerro Alcalá la vía seguía la vía pecuaria hasta Macha Real y después el camino de ésta a La Guardia hasta el lugar llamado Venta de Matías, en la carretera Jaén-Granada. Por aquí cruza el Guadalbullón y asciende unos $4 \mathrm{~km}$ hasta La Guardia.

El Itinerario pone Mentesa Bastiam en acusativo, por lo que podría darse aquí un caso de los que G. Arias habla en su teoría de los empalmes ${ }^{18}$ : la vía no llegaría hasta la misma ciudad de Mentesa, sino que en este lugar, Venta de Matías, había un empalme con una vía secundaria que atravesaba el río y ascendía hasta la ciudad, mientras la vía principal

Blázquez y Delgado Aguilera, A. y Bläzouez Jiménez, Op. cit., pág. 17.

HüBner, A., CIL II, pág. 451.

17 Plinio, C., Naturalis Historia, III, 10. Traducción por García Bellido, A., La España del siglo I de nuestra era. Madrid, Espasa Calpe, 1977, pág. 125.

is Arias, G. et al., Repertorio de caminos de la Hispania Romana. Madrid, G. Arias Edit, 1987, págs. 85-103. 
seguía por la margen derecha del río sin necesidad de atravesarlo en dirección a La Cerradura.

Otra hipótesis del trayecto Cástulo-Mentesa es que la vía tomara en las primeras millas la que desde Cástulo se dirigía a Córduba siguiendo la margen derecha del Guadalimar hasta lliturgi (Maquiz). En Mengíbar se desviaría de ésta en dirección Sur por Fuente Tétar y Jaén para seguir después a La Guardia. Tanto en este trayecto como en el de Cerro Alcalá la distancia es de uno $50 \mathrm{~km}$, aproximadamente las 32 millas del Itinerario.

P. Sillieres propone este itinerario, pero sin pasar por Aurgi (Jaén), siguiendo de cerca la orilla izquierda del Guadalbullón hasta llegar a La Guardia $^{19}$.

G. Arias propone un trazado muy diferente de todos los demás no sólo en este trayecto, sino en todos los siguientes. Localiza el empalme de Mentesa en Mancha Real y hace salir la vía por el Sureste de Cástulo hacia Lupión y Begijar, pasar el Guadalquivir por Puente del Obispo y llegar hasta Mancha Real, desde donde volvería, haciendo un violento recodo, hacia Jódar, donde localiza la mansión Viniolis. En realidad G. Arias, basándose en la teoría de Van Berchen de que el Itinerario de Antonino no es una guía de caminos, de lo que podríamos llamar en el lengua actual "de carreteras generales", sino una colección de los itinerarios impuestos a los destacamentos militares que tenían a su cargo la recaudación de la annona, parece que no busca la «carretera general» que utilizaban los viajeros que iban de Cástulo a Carthago Nova, sino la ruta que los jefes militares ordenaban recorrer a los soldados recaudadores de la annona, fuera o no por los caminos generales ${ }^{20}$.

De estas cuatro hipótesis a mí me parece más probable la primera, la de A. Blázquez, aunque con algunas variantes: en lugar de pasar por Torreblascopedro y Posadas Ricas, lo haría por Lupión, Begijar y Puente del Obispo, para seguir por Recena hasta Cerro Alcalá.

MENTESA BASTIA. Plinio habla de Mentesanos Bástulos y Mentesanos Oretanos ${ }^{21}$. El Itinerario Antonino pone a Mentesa Bastia como la primera mansión de esta vía entre Cástulo y Viniolis. En los Vasos de Vicarello figura otra Mentesa entre las mansiones Mariana y Libisosa.

19 Sillieres, P., Op. cit., pág. 286.

20 ARIAS, G., "El enredo bastetano", Miliario Extravagante, n. ${ }^{\circ} 25,1990$, págs. 10-18.

21 Plinio, C., Op. cit., n. ${ }^{\circ}$ III, pág. 25. 

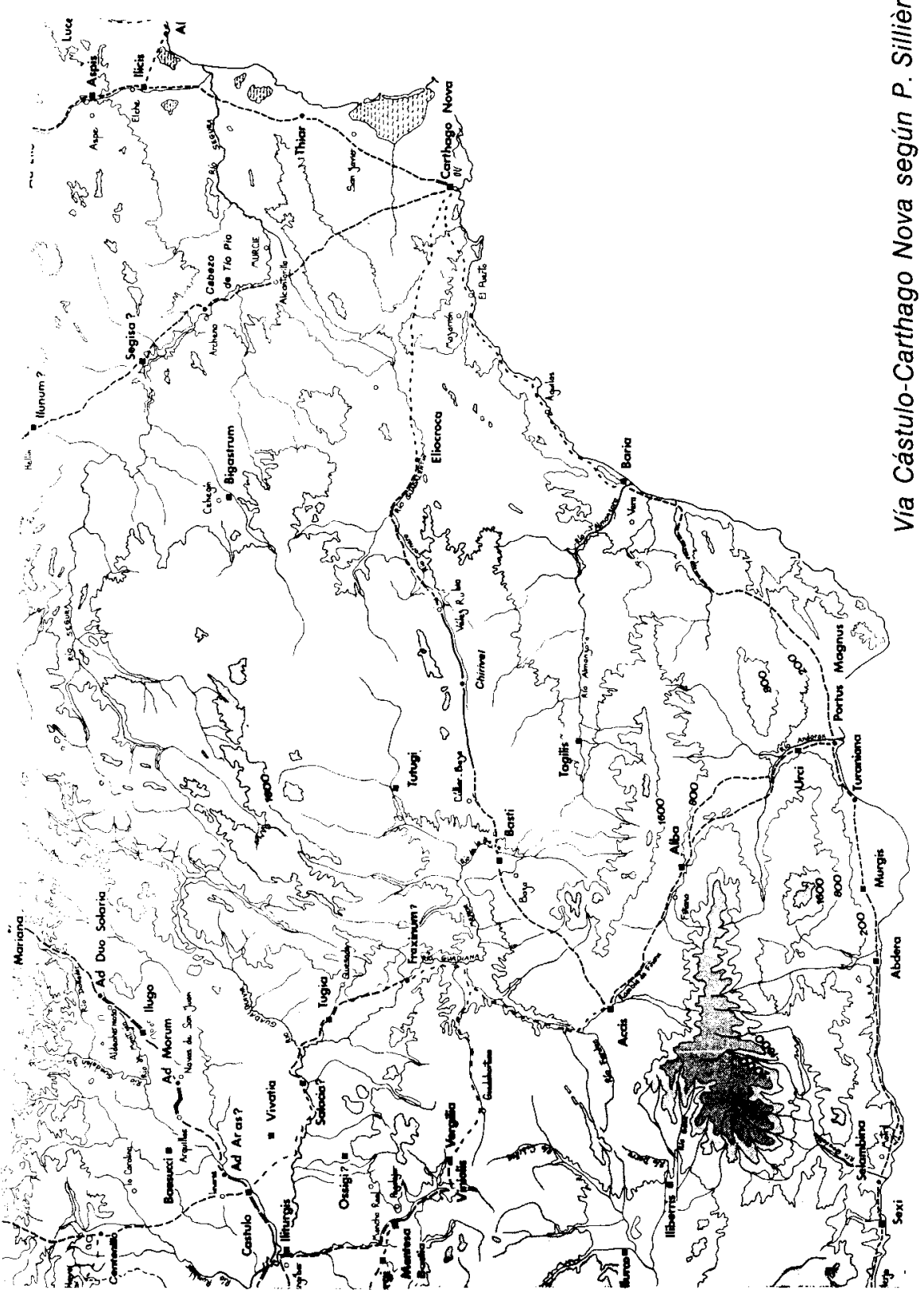


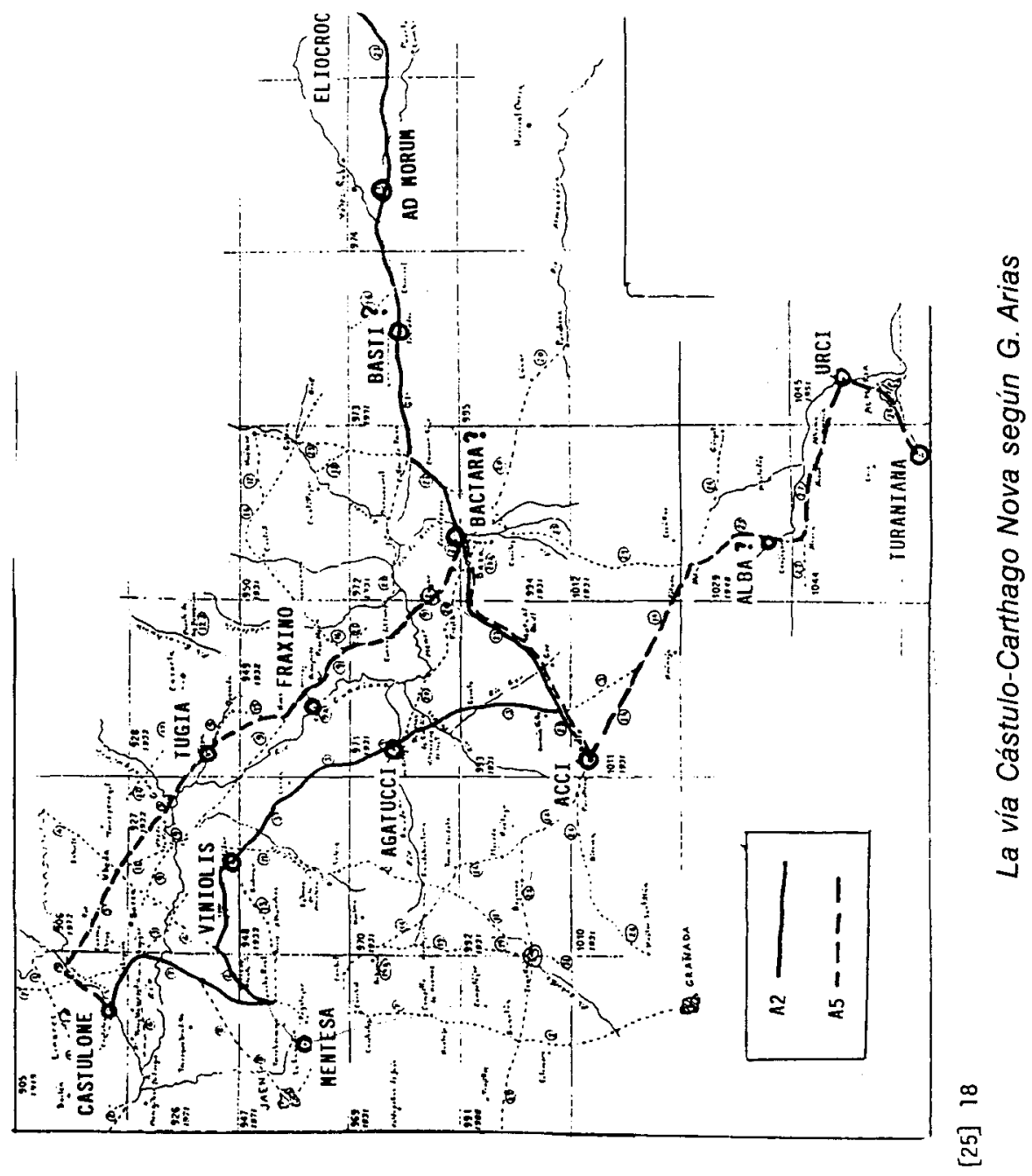




\section{VÍA CASTULO-SEATABIS}

Parece que los Mentesanos eran un grupo étnico pequeño que en parte estuvo sometido a los Oretanos y en parte a los Bastetanos. Y en ambas partes existió una ciudad con el nombre de Mentesa.

Mentesa Oretana suele localizarse en Villanueva de la Fuente (Ciudad Real). Mentesa Bastia en el actual pueblo de La Guardia, a unos $10 \mathrm{~km}$ al Sureste de Jaén.

Fue un puesto estratégico importante de la ruta entre Granada y Jaén por el Valle del Guadalbullón y desde la época ibérica hay señales de su importancia. Tanto en el casco urbano como en sus alrededores han aparecido numerosísimos restos ibéricos, romanos, visigodos y árabes, entre los que destaca un gran número de inscripciones romanas, en algunas de las cuales se menciona el ORDO MENTESANVS.

Fue zona fronteriza durante varios siglos entre moros y cristianos. Terminada la Reconquista, disminuyó su valor estratégico y ahora es un pequeño pueblo agrícola con feraces huertas en las márgenes del río.

TRAYECTO MENTESA-VINIOLIS-AGATVCCI-ACCI. Entre Mentesa Bastia y Acci el Itinerario de Antonino menciona las mansiones Viniolis y Agatucci. Existen notables discrepancias entre los diversos autores sobre la localización de estas dos mansiones, y por lo tanto sobre el trazado de la vía romana entre ellas.

A. Blázquez y otros suponen que la vía seguía junto al río Guadalbullón hasta el paso llamado de la Venta del Gallo, donde actualmente está el empalme de la carretera de Cambil con la de Jaén-Granada.

Aqui se desviaba hacia Oriente en dirección a Cambil, Huelma, Guadahortuna y Moreda. De la localización de Viniolis sólo dicen que estaba en el término de Cambil y de Agatucci Blázquez dice que en el Itinerario está fuera de lugar y que corresponde al tramo Acci-Carthago Nova, otros que se debe localizar en Huelma o Moreda o Alicún de Ortega ${ }^{22}$.

M. Góngora y E. Saavedra suponen que, desviándose del Guadalbullón también a la altura del empalme de Cambil, llegaría a este pueblo y después a Arbuniel, donde localizan Viniolis, y pasando después por Montejícar, llegaría a Iznalloz, que sería Agatucci. Después seguiria por Bogarre hacia Guadix ${ }^{23}$.

22 Góngora Martínez, M., Op.cit., fol. 30

23 Góngora Martinez, M., Ibidem. 
P. Sillieres también propone este trazado hasta Arbuniel y Montejícar, pero desviándose después a Guadahortuna y Alicún de Ortega donde localiza Agatucci. Después, por Villanueva de las Torres y Fonelas hasta Guadix ${ }^{24}$.

Hübner habla de una vía entre Aurgi e lliberri que coincidiría en líneas generales con la actual Jaén-Granada, si bien por la margen derecha del Guadalbullón, hasta Campotéjar, donde se bifurcaría: una en dirección a Granada por Benalúa de las Villas y otra a Guadix por Iznalldaloz ${ }^{25}$.

G. Arias descarta toda esta zona de la cuenca del Guadalbullón y la traza por la del Guadiana Menor por su margen derecha. Desde Jódar buscaba la cuenca del Guadiana Menor por Larva y Estación de Huesa hasta Alicún, donde localiza Agatucci. Después seguía por Dehesas de Guadix, Gorafe y Hernán Núñez hasta Guadix ${ }^{26}$.

De estas hipótesis me parece más probable la de Hübner, siguiendo un trazado muy próximo a la actual carretera Jaén-Granada, pero por la margen derecha del río, hasta el empalme de Cambil, en que pasa a la izquierda hasta Campillo de Arenas, donde podría localizarse Viniolis. Después de Noalejo y antes de Campotéjar se desvía un camino antiguo por Dehesas Viejas y Poloria hasta Iznalloz, en que se podría localizar Agatucci. Y de aquí por Bogarre, Venta del Puntal y Estación de Huélago a Guadix.

En estos lugares se han encontrado abundantes restos romanos y algunas inscripciones en Arbuniel, que parecen identificarla con la ciudad romana de Vergilia; una inscripción y algunos restos de columnas romanas en Campillo de Arenas y la ya famosa escultura del Togado de Periate cerca de Iznalloz, donde también se conserva un puente romano.

Apenas se sabe nada de vestigios romanos en Huelma, Moreda y Alicún de Ortega, los otros lugares propuestos para la localización de dichas mansiones.

ACCI COLONIA IVLIA GEMELLA. Está en el Itinerario, 402,1, en la vía Carthago Nova-Cástulo, entre Morum y Agatucci. Y en 406,6 , en la vía $A$ Castulone Malacam, ente Hactara y Alba. Era, por tanto el cruce de dos vías que comunicaban la zona minera del Alto Guadalquivir con los puertos mediterráneos (Carthago Nova, Urci y Malaca).

26 ARIAS, G., “El enredo bastetano", Miliario Extravagante, $n .^{\circ} 25,1990$, pág. 16. 
TRAZADO DE LA VÍA MENTESA-VINIOLIS-AGATUCCI

Hipótesis A A. Blázquez

Hipótesis B Góngora, Saavedra

Hipótesis C Hübner

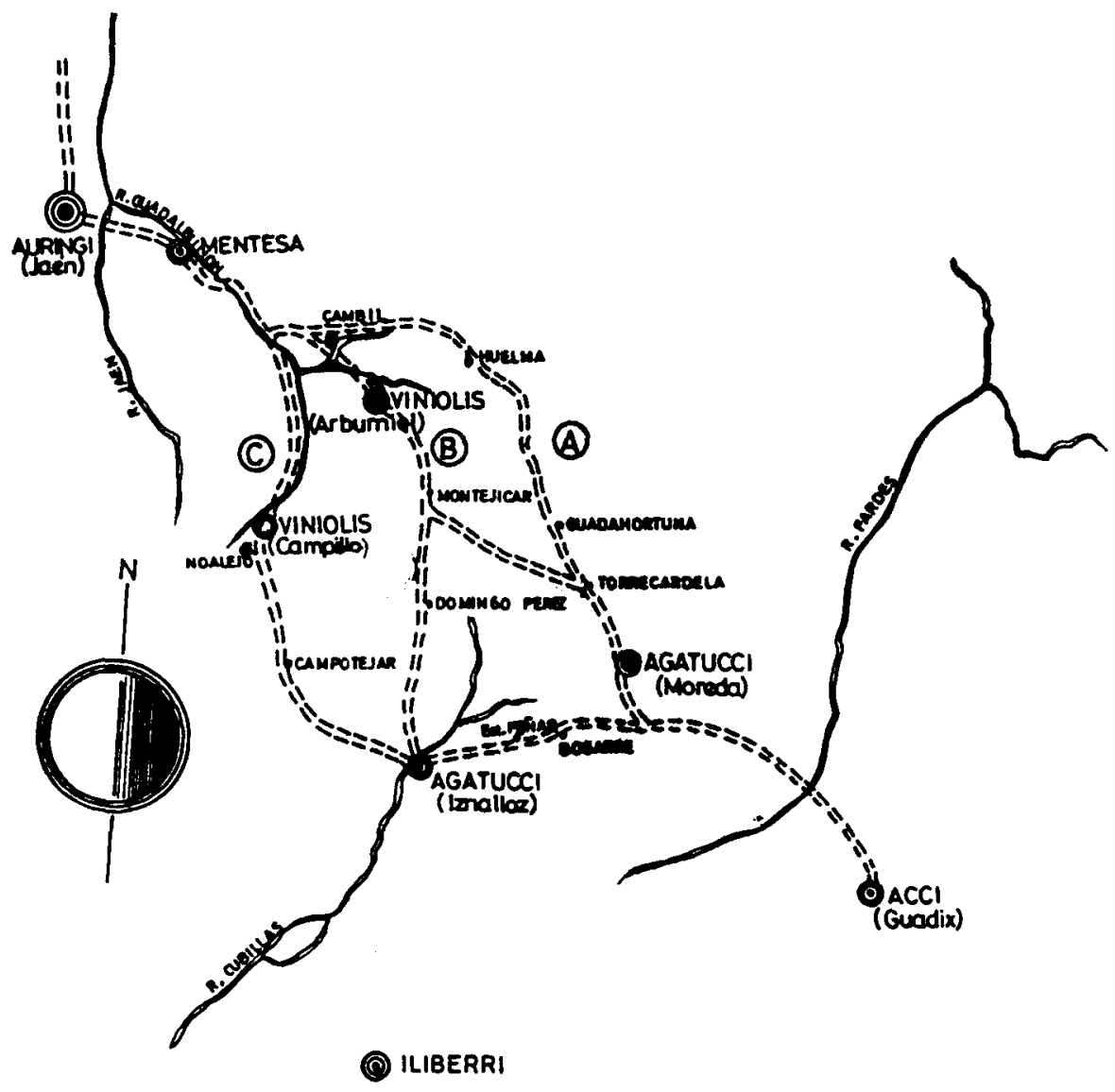


Es citada por Ptolomeo, Plinio, Macrobio y otros autores de la Antigüedad. Se han hallado numerosos testimonios epigráficos relativos a la Colonia lulia Gemella Acci. Hübner cita también un miliario dedicado a Póstumo, aunque dice que en su tiempo ya había desaparecido.

Estuvo situada en la actual Guadix, donde hubo asentamientos humanos desde épocas prehistóricas. En la época romana fue colonia del tiempo de César, a lo que alude el sobrenombre de lulia, tal vez con cedido después de la batalla de Munda, 45 a.C., y se llamó Gemella por las dos legiones | y || que estuvieron en ella estacionadas.

La mayor parte de la epigrafía de Acci corresponde a los siglos II y III, por lo que esta época sería la de mayor esplendor. Las inscripcciones hablan del culto a Isis, de dedicaciones a dioses, emperadores o emperatrices, de flamen augustal y de sevir augustal. Todo lo cual nos indica que fue colonia importante, con collegium de flamines y de seviri augustales, con la existencia de un culto imperial arraigado, un comercio intenso y una aristocracia municipal que constituía una élite social.

TRAYECTO ACCI-BASTI. La distancia de Acci a Basti es, según el itinerario, de 25 millas $(37,025 \mathrm{~km})$.

La carretera actual tiene $47 \mathrm{~km}$, por lo que Roldán Hervás supone que debe poner XXX $(44,430 \mathrm{~km})$ por la facilidad de confundir la $X$ con la $V^{27}$.

De Guadix a Baza hay dos caminos antiguos. A. Blázquez que los recorrió con la Comisión de la Junta Superior de Excavaciones y Antigüedades en 1923, propone el más corto, de siete leguas que, a 4 millas por legua, daría 28 millas.

El camino antiguo de Guadix de Baza es desde luego más corto que la carretera actual. Aunque en algunos tramos puede identificarse con ésta, en muchos tramos toma un trazado más directo y por tanto abrevia la distancia en 6 ó $7 \mathrm{~km}$ (localizando Basti en las proximidades de Cerro Cepero).

Saldría de las inmediaciones de la actual estación del ferrocarril y seguiría al principio la actual carretera, junto a la rambla de Baza, para, a unos $3 \mathrm{~km}$ después, desviarse a la derecha (camino de Guadix a Gor). También hay dos caminos hacia este pueblo: La Trocha, más directo y más corto, y el camino a Cortijo Nuevo, Curva del ferrocarril y camino de la Estación de Gor. En el primero ya cerca del pueblo de Gor en tiempos de Lafuente Alcántara existían restos de calzada. Actualmente en la parte

27 Roldán Hervas, J. M., Op. cit., pág. 52. 
llamada Cuesta de Guadix el camino está trazado por otro lugar un poco más al Norte del antiguo, pero aún quedan restos de éste bastante deteriorados por el tiempo, que probablemente son los que conoció Lafuente Alcántara. $Y$ en ellos aún se pueden apreciar restos del empedrado de la calzada.

También a la salida del pueblo, junto al cementerio, queda el camino antiguo hasta unirse con la carretera moderna a más de $1 \mathrm{~km}$ del pueblo. También en esta parte se pueden apreciar en algunos tramos los restos del empedrado antiguo; y por esta misma zona apareció hace algunos años una inscripción romana, que desapareció algún tiempo después.

A partir de su unión con la carretera actual los posibles restos están borrados por el asfalto.

El camino de Gor a Baza vuelve a la carretera Granada-Murcia hacia la Rambla y Venta del Baúl y el Romeral. Después de separarse otra vez por la izquierda y cruzarla de nuevo entra en la actual Baza por donde ahora está la plaza de toros y pasaba por la actual calle de los Alamillos, calle del Agua y Puerta de Lorca.

No se cree que en el casco urbano de la Baza actual estuviese la romana Basti. Pero si es probable que al pie de la Fuente de S. Juan, que está sobre Baza, y de las Siete Fuentes, algo más lejos, hubiese algún núcleo de población. Y que lo que actualmente es la Plaza de las Eras, calle Alamillos, Agua y Puerta de Lorca fuese el paso de la calzada por dicho núcleo.

Cuando el primitivo Basti, próximo a Cerro Cepero, fue abandonado, este pequeño núcleo se desarrolló considerablemente, llegando a ser la Baza árabe y actual.

BASTI. Fuera del Itinerario de Antonino, en que se cita la mansión Basti, entre Acci y Ad Morum, las menciones de las fuentes antiguas hablan de la región bastetana, pero no de la ciudad. El P. Flórez en «España Sagrada», T. V, índice de cosas notables, decía de este autor: «Pto lomeo cosmographo estuvo mal informado de cosas de España: omitió en los Bastitanos a su capital, colocó mal Lucentum...." ${ }^{28}$.

Las dos inscripciones relativas a Baza citadas por Hübner, CIL 3404 y 3405, tampoco mencionan a la ciudad. En cambio una inscripción aparecida cerca de Caravaca (Murcia) y dos de Cartagena muy parecidas están dedicadas a un personaje notable de Carthago Nova, Aemilius Rec-

28 FloRes, E., España Sagrada, t. V. Madrid 1763, pág. 578. 
tus, que era civis adlectus, scriba quaestorius y aedilicius en Carthago Nova y en diversas ciudades, entre ellas Asso (Caravaca) y Basti ${ }^{29}$.

Basti se identifica generalmente con Baza, que sigue siendo punto clave en las comunicaciones de la ruta Granada-Murcia a través del Surco Intrabético. Pero cuando se trata de concretar el lugar preciso en que estuvo situada la ciudad, ni los autores que han tratado el tema ni los mismos habitantes de Baza llegan a conclusiones claras.

En la época ibérica la tribu de los Bastetanos tuvo aquí su sede central, que debió ser importante a juzgar por las necrópolis de Cerro Cepero, Cerro del Santuario, donde se han encontrado gran cantidad de objetos ibéricos, y en 1968 la Dama de Baza, una de las esculturas más notables de la cultura ibérica, del siglo $v$ o Iv a.C.

También en las proximidades de Cerro Cepero y de Cerro Largo han aparecido abundantes vestigios romanos, que se suelen considerar de Basti: vestigios de edificios, entre ellos unos cimientos muy firmes de grandes piedras horizontales en la parte Sur de Cerro Cepero, que pudieran ser de un templo, asi como diversos objetos y alhajas de oro y plata y otros metales de valor, basas, capiteles, trozos de columnas, bustos, etc.

Lo más probable es que si no en el mismo Cerro Cepero, muy próximo a él y en la zona comprendida entre el mismo y el río de Baza, estuviese la Basti romana, destruida en las invasiones bárbara y árabe, y abandonada durante la dominación de estos últimos para asentarse en la actual Baza.

G. Arias localiza en este lugar la mansión Hactara o Bactara de la ruta "A Castulone Malacam», que a su vez sería la mansión omitida en esta Cástulo-Carthago Nova, de la que hablaremos después. Y la mansión Basti la localiza en el pueblo de Contador ${ }^{30}$.

TRAYECTO BASTI-MANSIÓN X. En el Itinerario de Antonino la distancia desde Basti hasta la mansión siguiente, Ad Morum, es de 16 millas $(23,696$ $\mathrm{km})$ y de aquí a Eliocroca $24(35,544 \mathrm{~km})$. En Total 40 millas $(59,240 \mathrm{~km})$.

En la carretera actual, que sigue un trazado muy aproximado, hay de Baza a Vélez Rubio $67 \mathrm{~km}$ y de Vélez Rubio a Lorca 45 , en total $112 \mathrm{~km}$.

Hay por tanto una diferencia de más de $52 \mathrm{~km}$, que parece excesiva para explicarla por alguna variante en el trazado.

29 YeLO, A., "Asso. Hacia un nuevo planteamiento sobre su localización cerca de Caravaca", Anales de la Universidad de Murcia XLII, n. ${ }^{\circ 3} 3-4,1983-1984$.

${ }^{30}$ ARIAS, G., Op. cit., pág. 16. 
A. Blázquez trata de solucionar esta laguna haciendo un cambio de la. mansión Agatucci, que según él, estaría fuera de lugar entre Viniolis y Acci.

A. Blázquez lleva razón en que entre Basti y Ad Morum falta una mansión y unas 30 millas. Pero ya vimos que la mansión Agatucci no está demás en el trayecto anterior.

Esta mansión omitida, que podríamos llamar mansión $X$ mientras no dispongamos de nuevos datos, podría corresponder al poblado de las Vertientes o a Contador o a Chirivel.

De estos tres poblados parece que Chirivel es el más indicado para localizar la mansión omitida, tanto por las distancias como por la abundancia de restos romanos encontrados en él.

G. Arias localiza en Contador la mansión Basti y en Baza localizaba la mansión Hactara de la vía Cástulo-Malaca ${ }^{31}$.

En el trayecto entre Baza y Chirivel se encuentra el pueblo de CúllarBaza. En 1973 en una cortijada próxima a este pueblo, Pulpite, junto a la Rambla de Venta Quemada un agricultor que extraía arena en el lecho seco del riachuelo descubrió un miliario que fue estudiado por $P$. Sillieres y publicado en el Congreso de Historia de Andalucía en diciembre de 1976.

Sillieres, que visitó el lugar, dice que el mojón no estaba en el lugar de emplazamiento, sino que había debido caer al barranco después de alguna crecida y en seguida haber sido arrastrado algún trecho. Es verosímil que provenga de un punto bastante vecino del lugar del hallazgo. Fue después instalado en el Altar Mayor de la Iglesia Parroquial de Cúllar, donde se encuentra actualmente ${ }^{32}$.

Está dedicado a Augusto y corresponde a los años 6-7 a.C. época en que Augusto mandó construir esta calzada y que $P$. Sillieres relaciona también con la reestructuración de las provincias Bética y Tarraconense, en que esta zona pasó de la primera a la segunda.

De Cúllar cita Hübner otros dos miliarios en CIL II 4941. El Anónimo Accitano (el Abad Navarro), de quien Hübner toma los datos, habla de dos columnas, una que estaba enterrada en la arena de la rambla de Venta Quemada, de la que no hace transcripción, y otra que estaba en

\footnotetext{
31 ARIAS, G., Ibidem.

32 Sillieres, P., "Un nouveau milliaire d'Auguste decouvert a Cullar de Baza (Grenade)", Actas del I Congreso de Historia de Andalucia, 1976. Jaén, págs. 355 y ss.
} 
una ermita de Cúllar, que es la que transcribe, y que parece debe atribuirse también a Augusto. Es posible que la enterrada en la arena, de la que el Abad Navarro tuvo noticia por un labrador de Venta Quemada, sea precisamente la descubierta en 1973 por otro labrador del mismo pueblo.

La actual carretera de Cúllar, que pasa al Sur del pueblo es moderna. La carretera antigua Granada-Murcia, y el camino antiguo, pasaba por la parte alta, al Norte, y seguía unos $3 \mathrm{~km}$, que todavía se utilizan como camino agrícola. Después se acercaba a la Rambla de Venta Quemada y continuaba bordeando la misma a unos cientos de metros al Sur de la carretera actual. Estos miliarios han aparecido junto a la Rambla.

MANSIÓN X (Chirivel). Decíamos que de los lugares propuestos para localizar la mansión omitida en el Itinerario nos parece que el más probable es Chirivel. Las 24 millas de Eliocroca a Ad Morum parecen situar esta mansión en los llanos de Viotar o en Charche Bajo, al Sureste de Vélez Rubio. Y las 16 siguientes que el Itinerario pone hasta Basti no pueden aplicarse a Baza, que está a 47 millas del campo de Vélez Rubio, sino a la mansión omitida y que a nuestro parecer es Chirivel.

Antes de llegar a Chirivel desde Baza está el poblado de las Vertientes, donde apareció otro miliario atestiguado por Navarro y citado por Hübner, CIL II 4940; pero sólo podían leerse algunas letras sueltas y era imposible de descifrar.

Chirivel está situada en un valle dilatado entre las sierras de María al Norte y la de Oria al Sur y a las márgenes de un arroyo que viene de Las Vertientes. Además de gran cantidad de restos romanos de todas clases, el Abad Navarro habla de inscripciones y de dos columnas (miliarios), una en la casa de Abajo, dedicada a Caracalla ${ }^{33}$ y otra que se guardaba en la casa del Cura, dedicada a Numeriano. (CIL 4942). Un tercer miliario en el Pago del Fraile, también término de Chirivel, está dedicado a Augusto. (CIL 4938).

El Abad Navarro en su manuscrito sobre el pueblo de Chirivel termina diciendo: "Otras muchas inscripciones ha desperdiciado la ignorancia de aquellos vecinos: pero estas reliquias de la Antigüedad Romana indican pueblo de alguna consideración, pues en él había muchos y magníficos baños, plazas grandes, estatuas y dedicaciones a Emperadores" ${ }^{34}$.

TRAYECTO MANSIÓN X-AD MORVM. Desde Chirivel la vía romana continuaba por la margen izquierda de su rambla en dirección a Vélez Rubio.

33 Fita, F., Op. cit., pág. 488

34 Fita, F., lbidem, pág. 489. 
Comunicaciones entre el Alto Guadalquivir y el Mediterráneo en la época romana

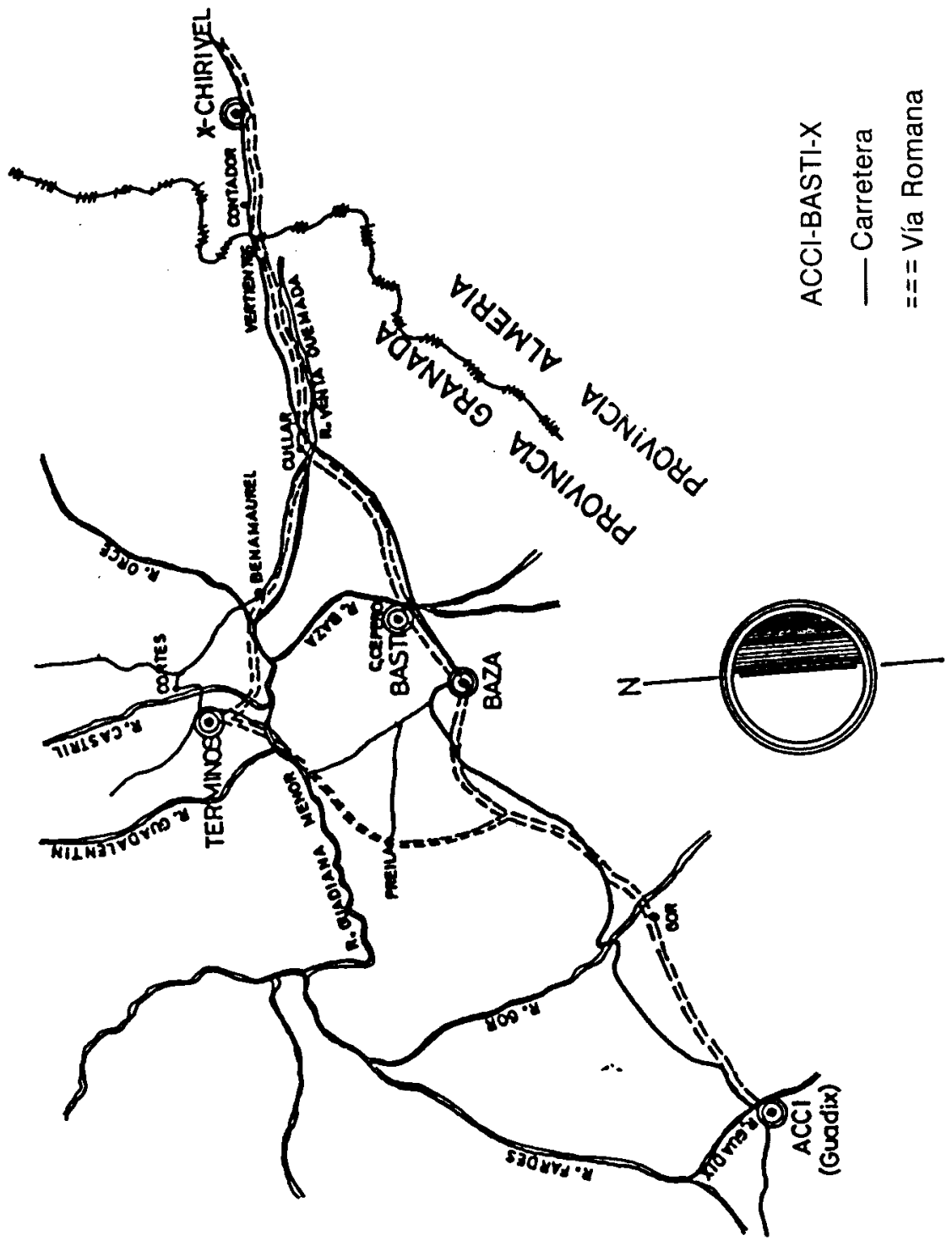

369 
A unos $6 \mathrm{~km}$ está el Pago del Fraile, donde apareció el miliario del que hablamos anteriormente. $1 \mathrm{~km}$ más adelante a la Rambla de Chirivel se le une por la derecha la de Claví. Por el valle de esta rambla se desviaba la vía romana en dirección a la cabecera de la Rambla del Centeno y Jinte, dejando la dirección de Vélez Rubio que sigue la carretera actual. Por esta zona es por donde decía el Abad Navarro que había un carril poco usado en su tiempo que, según los vecinos de Vélez, había sido camino de romanos y por él "se conduxeron las lombardas con que se combatió Baza». Por allí también en tiempos de Navarro estaba visible la calzada en largos tramos y había noticia de miliarios.

En el Pago de los Alamicos, ya al Sur de Vélez Rubio, apareció otro miliario o columna, que fue llevado a Vélez Rubio por un labrador para servir de escalón en la puerta de su casa. La mayor parte de las letras habían sido picadas, por lo que no se podía hacer una lectura segura con las pocas que quedaban.

A propósito de este miliario y esta zona el Abad Navarro refiere una anécdota de un maestro de latinidad que leyó en él la palabra Morum y dijo que aquella piedra decía que Vélez fue en tiempo de los romanos una ciudad llamada del Moral. Navarro, que no había pensado que en este tramo hubiese una mansión omitida, había supuesto la localización de Ad Morum al hablar de Chirivel. Y ahora en las proximidades de Vélez Rubio sospecha la localización en este lugar. Las distancias del Itinerario vienen mejor en las proximidades de Vélez Rubio para Ad Morum y en Chirivel para la mansión omitida, a 16 millas del campo de Vélez Rubio.

AD MORVM. Esta mansión de la vía Cástulo-Carthago Nova (hay otra con el mismo nombre en la vía Cástulo-Saetabis) se ubica tradicionalmente en el límite de la provincia de Almería con la de Murcia, en el término de Vélez Rubio o cerca de Xiquena, donde existen restos de población romana.

Según A. Blázquez la vía no iba por esta parte del castillo de Xiquena, sino al Sur de Vélez Rubio, siguiendo por Los Alamicos, Tonosa, Charche Bajo y los Llanos de Viotar ${ }^{35}$.

Por el Charche Bajo y Llanos de Viotar se entra en un terreno más afable y fértil, donde se halló otra de las columnas, tan maltratada que no se pudo leer. En esta zona de los Llanos de Viotar es donde mejor coincide la distancia de las 24 millas desde Lorca y las 16 desde Chirivel.

35 Blázquez Delgado Aguilera, A. y Blázouez Jiménez, A., Op. cit., pág. 16. 
P. Sillieres y otros autores disienten de este trazado y esta localización. Opinan que la vía romana no pasaba al Sur de Vélez Rubio, sino que seguía como la carretera actual hasta esta población y después en dirección Nordeste, como la Rambla de Chirivel, seguía hasta el río Corneros, El Jardín y Castillo de Xiquena. En El Jardín debería localizarse la mansión Ad Morum. En la zona existen yacimientos argáricos y romanos.

Esta zona ha sido en efecto paso entre Lorca y Vélez Rubio desde tiempos prehistóricos y la existencia de los castillos de Xiquena y Tirieza indican que también en la Edad Media siguió siendo paso importante.

TRAYECTO AD MORVM-ELIOCROCA. Después de Charche Bajo y de los Llanos de Viotar la vía vuelve a encontrarse con la carretera GranadaMurcia, pero tampoco hace el arco de la carretera moderna hacia Puerto Lumbreras, sino que toma el camino de las Peñas de Béjar, junto a la Rambla de los Casarejos. "Los restos de las columnas miliarias, dice el Abad Navarro, indican que el camino romano se dirigió con alguna diferencia cortando los ángulos que hoy hace la carretera en Vélez Rubio y Lumbreras, que entonces no existían" ${ }^{36}$.

Desde las Peñas de Béjar continuaba por la rambla de este nombre hasta adentrarse en la llanura, donde se encuentra de nuevo la carretera que viene de Puerto Lumbreras, siguiendo ya la dirección de ésta hasta entrar en Eliocroca.

En este tramo, unos $4 \mathrm{~km}$ antes de llegar a la actual Lorca, está la Torrecilla, un cerro de mediana altitud coronado por una torre atalaya, y la Rambla de la Torrecilla, entre este cerro y el de Cabezo del Pino. En una finca de esta zona, la Casa de las Ventanas, se descubrió en 1926 una extensa necrópolis romana que revela la existencia de una importante y populosa población.

En el otro trazado, que localizaba la mansión Ad Morum en El Jardín o en las proximidades de Xiquena, desde El Jardín pasaría junto al castillo; después por Fontanares y el poblado de Fuensanta, dejaría al Norte el Pantano de Fuentes, y por la orilla derecha del río Guadalentín llegaría a Lorca.

Madoz habla de estos dos trazados en los caminos antiguos de Lorca: "Un camino al Puerto Lumbreras, por donde se entra en la Rambla de Nogalte para salir a Vélez Rubio y otro por medio del río al castillo de Jequena, el cual es el que lleva la arriería de Granada» ${ }^{37}$.

${ }^{36}$ FITA, F., Op. cit., pág. 490

$37 \mathrm{MADOZ}, \mathrm{P}$., Diccionario geográfico-estadístico-histórico de España y sus posesiones de ultramar. Madrid, 1846-1849, art. Lorca. 
A nosotros nos parece más probable la opinión de Navarro, señalando la vía romana por el primero, pero sin llegar a Puerto Lumbreras ni a Vélez Rubio.

En este tramo hay una parte de terreno muy dificultoso, tanto por el Sur de Vélez Rubio, como por la zona de las Peñas de Béjar; pero luego hay otro tramo completamente llano desde la salida de las Peñas hasta Lorca.

En el otro trazado (por Xiquena) la primera parte del camino es menos difícil, pero la siguiente hasta Lorca también es de gran dificultad.

ELIOCROCA. Por la similitud del nombre y por la distancia con Carthago Nova se identifica con Lorca.

Hübner cree que Eliocroca, solamente citada en el Itinerario de Antonino, 401,6, correspondería a alguna localidad de escasa importancia, correspondiendo Lorca a llorci. No descarta sin embargo la localización de Lorca.

Otros muchos autores han identificado Lorca con la llorci de que hablan las fuentes antiguas. El pasaje de Plinio en que habla del río Betis y dice que «en llorci se aleja de la hoguera en que Escipión fue quemado y dirigiéndose al ocaso da su nombre a la provincia» ${ }^{38}$, ha sido interpretado como referido al río Tader, del que hay una referencia incidental en el texto pliniano, y aplican el topónimo Ilorci a Lorca, por ser en el Campo Cartaginense el de más parecido; y asimismo sitúan en esta región la torre en que Escipión fue quemado.

En realidad el pasaje de Plinio se refiere alrío Baetis, y las luchas de los Escipiones, en las que ambos hermanos murieron en 211 a.C., se localizan en las proximidades de Cástulo, en la región del Alto Guadalquivir.

En general se considera que Eliocroca corresponde a Lorca y la Ilorci de Plinio a alguna ciudad del Alto Guadalquivir, probablemente la misma lliturgi.

En Lorca se han encontrado vestigios de poblamiento ibérico tanto en el núcleo urbano como en las zonas próximas. De la época romana, además de la necrópolis de la Torrecilla, con sus inscripciones funerarias, en la misma casa en que aparecieron vestigios ibéricos apareció una tumba romana. La reliquia romana más característica de Lorca es el famoso mi-

38 Plinio, C., Op. cit., pág. 124. 


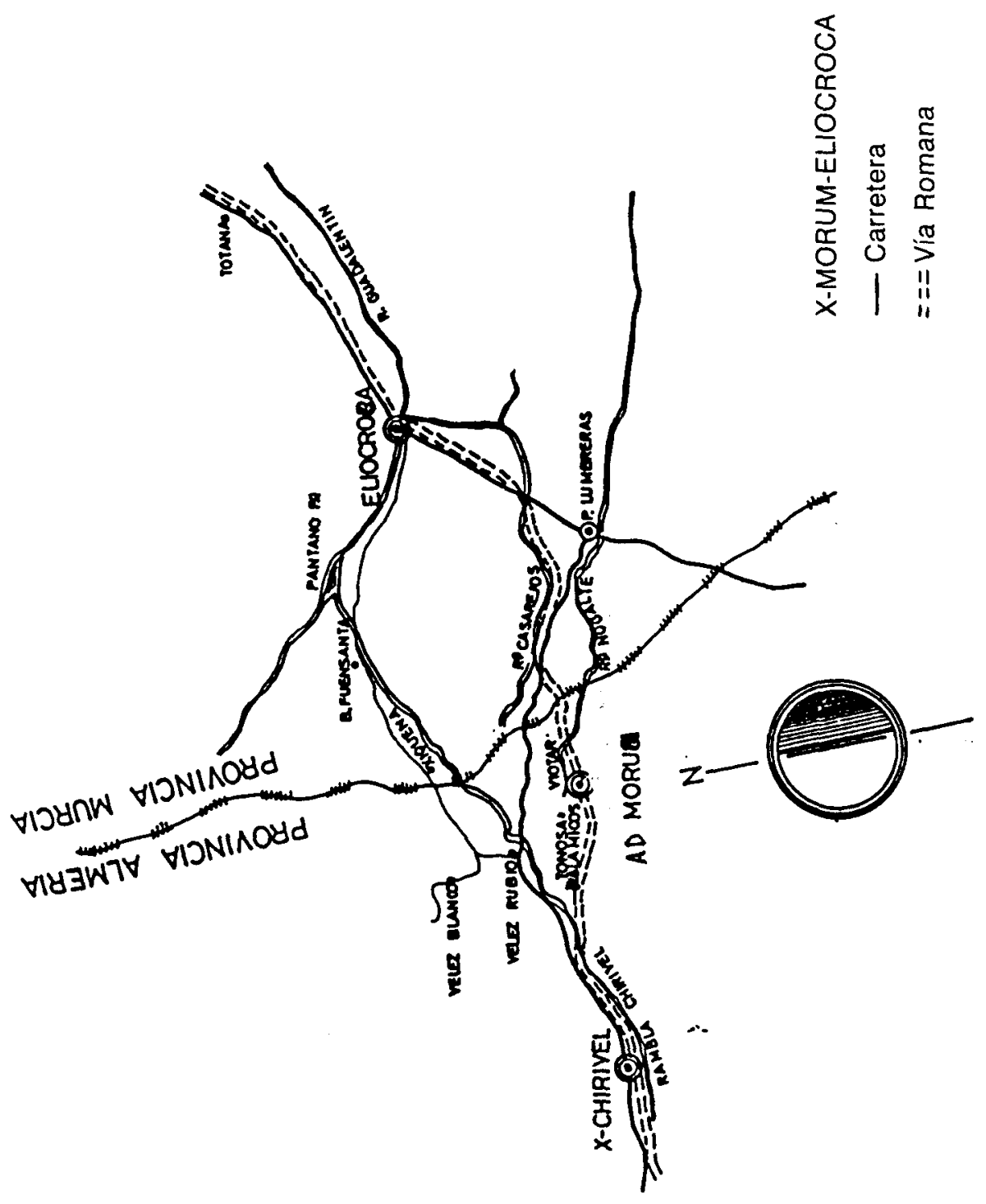


liario de S. Vicente, que, a pesar de los avatares que ha sufrido a lo largo de los siglos, parece que está poco más o menos donde pasaba la vía romana, ya que la actual Corredera de Lorca pudo tener su origen en el antiguo Camino Real y éste en una vía romana.

En los alrededores de Lorca han aparecido también vestigios de aldeas o villas de la época romana: un mosaico polícromo en La Quintilla, cerámica y escultura romana en la Torre del Obispo y restos de una villa romana en la Tejerica, en paraje del Villar.

TRAYECTO ELIOCROCA-CARTHAGO NOVA. Las 44-48 millas, según las lecturas $(65,164-71,088 \mathrm{~km})$ del Itinerario, son una jornada muy larga para hacer el recorrido en un día. Pero es en general terreno llano y sin dificultades y tal vez por eso el Itinerario no haya señalado ninguna mansión intermedia.

«El camino directo Cartagena-Lorca ha sido recorrido por la Comisión (de la Junta Superior de Excavaciones y Antigüedades) en varios kilómetros: es Camino Real y fue vía romana, midiendo $66 \mathrm{~km}{ }^{39}$.

Este trazado supone que la vía romana, antecesora del Camino Real, no pasaba por Totana, sino por Corral Rubio, Venta del Herrero, Loma de Lardín, Cánovas y Fuente Álamo.

Un poco más al Sur había otra vía pecuaria hacia La Pinilla, donde hay restos romanos y una inscripción en verso. Hübner en el mapa del Supplementum hace pasar por La Pinilla una vía Lorca-Cartagena.

Pero hay también vestigios de camino romano entre Totana y Cartagena, que pasaría por Cuevas de Reyllo y Fuente Álamo, con un desarrollo de $50 \mathrm{~km}$ y de Totana a Lorca con 21.

Esta distancia cuadra mejor con la lectura de $\mathbf{4 8}$ millas, que a su vez viene mejor con la suma total de 149 entre Acci y Carthago Nova.

Hübner cita de Totana el miliario 4936, en el que figura la cifra de 22 millas. Esta es una cifra demasiado corta para el tramo Totana-Cartagena, así como serian excesivas las 26 restantes de Totana a Lorca. La distancia real es de unas 32 millas en el primer tramo y de unas 16 para el segundo.

También dice Hübner que el miliario indica la mitad de la distancia entre Lorca y Cartagena y que Totana está precisamente en la mitad del camino. En realidad no está en la mitad, sino bastante más cerca de Lorca 





$(22 \mathrm{~km})$ que de Cartagena $(49 \mathrm{~km})$, por to que el miliario, o procede de un lugar distinto de Totana, o tiene borrada alguna cifra.

"Así pues, si aceptamos el número de millas de 48 , suman $71 \mathrm{~km}$, y hay que adoptar el camino por Totana; pero si consideramos buena la lectura de 44 millas, entonces se impone el Camino Real directo con trozos visibles de calzada en varios lugares ${ }^{40}$.

En Totana han aparecido abundantes restos romanos y algunas inscripciones. El historiador local J. Munuera dice que cuando en 1602 se construía el atrio del actual convento de S. Buenaventura, se descubrió parte de una vía romana, cuya base estaba formada de tierra y arena, y sobre este lecho descansaba una capa o firme de grandes sillares perfectamente labrados, colocados con gran precisión; piedras que se utilizaron para la edificación del mencionado convento ${ }^{41}$.

También apareció allí el miliario de que hablamos anteriormente, formado por un pedestal de base cuadrada sobre el que se elevaba una columna cilindrica de $1,90 \mathrm{~m}$ de altura, que contenía la inscripción latina. Durante muchos años estuvo en el patio del Convento, pero en la actualidad no existe.

En varios puntos del trayecto que media entre Totana y el río Guadalentín se encontraron piedras del mismo origen que las habidas en el atrio del convento de Totana, pero donde existían mayores y más importantes restos de la vía fue en el mismo río, donde quedaban restos de un puente en el lugar llamado el Paretón, y muy próximo restos también muy antiguos de una presa de la que se conservaban muestras en el siglo XVI.

Después de el Paretón la vía pasaba por Cánovas Cuevas de Reyllo y Fuente Álamo. Y siguiendo la vía pecuaria se acercaba a la Rambla de Benipila por La Guía, Los Dolores y S. Antón.

La ciudad romana de Carthago Nova era muy diferente de la actual Cartagena. Era una península bañada en la parte superior por un estero - laguna, actualmente desecada y sobre la que está edificada la mayor parte de la ciudad moderna; por el puerto, que ocupaba lo que ahora es la dársena del arsenal, si bien las aguas llegaban hasta lo que ahora se llama Puertas de Murcia, y hasta la falda del cerro Molinete; y por el actual puerto de Cartagena.

40 Blázquez delgado Aguilera, A. y Blázquez Jiménez, A., Ibidem, pág. 23.

41 Munuera, J., Apuntes para la historia de Totana y Aledo. Totana 1916, pág. 44. 
La vía desde Fuente Álamo entraba en Cartagena junto a la Rambla de Benipila y pasaba a Carthago Nova atravesando el puente sobre el canal que unía el estero con el puerto. El canal y el puente estaban en lo que ahora son las Puertas de Murcia: y por la calle Honda la vía llegaba al centro de la ciudad. 